\title{
DEBATE
}

\section{A future like ours revisited}

\section{T Brown}

Correspondence to: Professor M T Brown, University of Wisconsin Marathon County, 518 South 7th Avenue, Wausau, WI USA; mbrown@uwc.edu 2 December 2001
It is claimed by the future like ours anti-abortion argument that since killing adult humans is wrong because it deprives them of a future of value and the fetus has a future of value, killing fetuses is wrong in the same way that killing adult human beings is wrong. In The morality of abortion and the deprivation of futures (this journal, April 2000) I argued that the persuasive power of this argument rests upon an equivocation on the term "future of value". If the expression means "a potential future of value" then the moral claim is implausible because people do not in general have rights to what they need to fulfill their potential; if the expression means "self-represented future of value" then the argument fails because the fetus does not represent its future. Under no interpretation is the argument sound. In Deprivations, futures and the wrongness of killing (this journal, December 2001) Donald Marquis, author of the future like ours argument, responds at length to this objection. In the present essay the focus of the debate shifts to the proper interpretation of the right not to be killed. Donald Marquis argues that this liberty right entails the welfare right to the means necessary to sustain life; I argue that the right not to be killed does not entail unlimited welfare rights. On Marquis's view, the right not to be killed confers upon the fetus the right to whatever it takes to sustain life; on the view I defend, the right not to be killed does not confer upon the fetus or anyone else the right to another person's body. On Marquis's view, abortion is almost never permissible; on my view abortion is almost always permissible.
M $y$ purpose in The morality of abortion and the deprivation of futures (this journal, April 2000) ${ }^{1}$ was to diagnose the intuitive appeal of the future like ours anti-abortion argument in terms of an unnoticed equivocation on "a future of value" and to show that on either of the most plausible interpretations of this expression, the future like ours argument was unsound. ${ }^{1}$ I thought a critique of the future like ours argument was worth doing because it is one of the few anti-abortion arguments that do not depend explicitly or implicitly on theological premises rooted in ecclesiastical or scriptural authority.

My purpose in this essay is to demonstrate that Donald Marquis's attempt to rehabilitate the future like ours argument in Deprivations, futures and the wrongness of killing, published in the Journal of Medical Ethics December 2001, rests upon a misreading of The morality of abortion and the deprivation of futures. ${ }^{2}$ For this reason it will be necessary to take a close look at the precise language and arguments Marquis employs in an effort to save the future like ours argument. Marquis's interpretation of my argument is also marred by logical errors which lead him to attribute to me implausible moral claims that I neither endorsed nor are implied by any claim I did endorse. Readers interested in unravelling these mistakes are referred to the appendix.

There may be other as yet unstated anti-abortion arguments founded upon intuitions regarding lost futures of aborted fetuses, but if the future like ours argument is fatally flawed, then this most influential version of futurist antiabortion arguments can be laid to rest. Anti-abortion advocates in liberal democracies founded on religious toleration and separation of church and state will have to look elsewhere for a non-sectarian defence of stringently antiabortion public policies.

The future like ours argument appears to capture what many people find objectionable about abortion: An innocent human being is killed and thereby deprived of a future of love, laughter, accomplishment and everything else that makes life meaningful. Here is Marquis's most recent formulation ${ }^{3}$ :
The future like ours argument

Premise 1: Having a future of value is the basis for the right not to be killed.

Premise 2: Fetuses have a future of value.

Conclusion: Fetuses have the right not to be killed.

My argument in The morality of abortion and the deprivation of futures was that the future like ours Argument equivocates on the expression "future of value"; and that on either interpretation, the argument is unsound. Call this the equivocation objection. Future of value could mean that actual persons have a potential future of value in the sense that given favourable conditions they are likely to have a worthwhile life; or future of value might mean that actual persons have a selfrepresented future of value in the sense that they can construct mental representations of valuable futures. The expression must be used consistently throughout if the argument is to be sound. But if future of value is consistently interpreted as meaning potential future of value, then the future like ours argument is unsound because premise 1 implies implausibly strong welfare rights; and if future of value is consistently interpreted as meaning self represented future, then the future like ours argument is unsound because premise 2 implausibly attributes self consciousness to the fetus. Either way the future like ours argument is unsound.

\section{STRONG LIBERTY RIGHTS}

Marquis's arguments in response to the equivocation objection cluster around the two interpretations of future of value that we both accept as most plausible. The first cluster focuses upon an argument Marquis attributes to me. ${ }^{4}$

The potential future of value welfare rights argument

Premise 1: If having a potential future of value is the basis for the right not to be killed, then humans have a welfare right to what they need to stay alive. 
Premise 2: Humans do not have welfare rights to what they need to stay alive.

Conclusion: Having a potential future of value is not the basis for the right not to be killed.

As Marquis notes, premise 1 of the potential future of value welfare rights argument as stated is implausible. The right not to be killed is a non-interference or liberty right, essentially a right to be left alone, and liberty rights in general do not entail welfare rights to various goods and services. What Marquis overlooked is that there is an exception to this rule: when the exercise of a liberty right by its nature makes claims upon goods and services to which the person is not otherwise entitled, then a claim to the liberty right implies a claim to a welfare right. To will the end is to will the means. For example, free speech generally is considered a liberty right, but if one were to claim a free speech right to address the public at large such a claim would imply a welfare right to print, television, or other media to which one is not otherwise entitled. Owners of these resources may be inclined to reject such strong liberty rights.

The South African AIDS epidemic suggests an analogy to the strong liberty rights claims of some anti-abortionists. In South Africa many people believe that intercourse with a virgin prevents or cures AIDS. Assume for the moment that this strange and pernicious belief were true. Many HIV-positive people in South Africa reasonably believe that the disease will kill them before they receive effective medical treatment. Such people might claim that their liberty right to life implies the welfare right to rape 11 year old girls. A girl about to be raped by such a man may have the well-founded belief that nothing short of lethal force will fend off the attack. Assume that she has attempted to prevent the rape by all the non-lethal means available to her. Does the rapist's right not to be killed imply that he has a welfare right to rape a child? In order to make this case as close as possible to the case of abortion, assume also that just as the fetus is innocent, the rapist does not have a guilty mind. Perhaps he fails to satisfy the legal doctrine of mens rea because he is delusional about matters other than his medical condition, or perhaps he is under the influence of post-hypnotic suggestion or powerful drugs which create in him an irresistible impulse to commit this crime. Clearly, this liberty rights claim is much too strong, precisely because the right of another person not to be killed does not imply a welfare right to another person's bodily integrity.

Consider now the case of abortion. A claim on behalf of a fetus to the right not be killed implies by its very nature a welfare right to access to the body of a quite specific woman. In most cases the fetus cannot be removed from the body of the woman without killing the fetus and the woman cannot exercise her liberty right to bodily integrity as she chooses as long as the fetus resides within her. Anti-abortionists claim that the right of the fetus not to be killed overrides the right of a woman to bodily integrity. Women who claim the right to an abortion reject liberty rights claims made on behalf of the fetus to welfare rights to a woman's body, just as nearly everyone would reject claims to welfare rights to a woman's body in the South African scenario. Just as most pregnancies do not imperil the lives of pregnant women, most rapes do not result in the death of their victims; just as the fetus is innocent because it has no intentions, one can imagine the rapist innocent due to mental incapacity; just as rape can lead to dire emotional, physical, and social consequences, an unwanted pregnancy can disrupt every aspect of a woman's life; just as the life of the fetus depends upon access to the reproductive system of a woman, the life of the HIV-positive rapist is (assumed to be) dependent upon access to the reproductive system of a child, and just as a just legal system would protect the child from the rapist by any means necessary up to and including the use of lethal force, a just legal system would protect the right to an abortion.
The welfare rights argument can be restated in a form that makes explicit the commitment by defenders of the future like ours argument to implausibly strong liberty rights:

The complete potential future of value welfare rights argument

Premise 1: If having a potential future of value is the basis for a right not to be killed that is sufficiently strong to protect the fetus in utero, then humans have welfare rights to the bodily integrity of other persons.

Premise 2: Humans do not have welfare rights to the bodily integrity of other persons.

Conclusion: It is false that having a potential future of value is the basis for a right not to be killed that is sufficiently strong to protect the fetus in utero.

We may conclude that a potential future of value interpretation of the future like ours argument strong enough to entail its anti-abortion conclusion is committed to implausibly strong welfare rights. Here is what a fully explicit version of Marquis's argument would look like:

The complete future like ours argument

Premise 1: Having a future of value is the basis for a right not to be killed that is sufficiently strong to protect the fetus in utero.

Premise 2: Fetuses have a future of value.

Conclusion: Fetuses have the right not to be killed.

We should reject premise 1 of this version of the future like ours argument if we reject the rights of rapists in the South African scenario and similar situations.

The need for an abortion can be very intense, comparable in some cases to the drive to fend off sexual assault. In other circumstances, the desire to terminate a pregnancy is less pressing, both as judged from without and as experienced from within. Consider a woman who enters the third trimester of an uneventful pregnancy carrying a healthy 24 week fetus. A viable infant could be delivered if labour were induced, an infant that is intrinsically no different than the fetus it was. Assume that suitable adoptive parents eagerly await childbirth, perhaps the infant's grandparents or biological father. Assume also that as a matter of fact the woman has formed no deep maternal bond with the fetus and is prepared socially, vocationally, and emotionally to pick up where she left off before she became pregnant. Her pregnancy will have to be medically managed somehow, whether she gives birth or undergoes a therapeutic abortion. Surely the right thing to do in this situation is to bring the pregnancy to term. It would be selfish for her not to sacrifice so little to do so much good.

A woman who chooses to terminate her pregnancy in this situation is a much less sympathetic figure than an 11 year old rape victim, but a person's right to bodily integrity does not depend upon the quality of his or her character. People with rare blood types are entitled to decline requests for lifesaving blood donations; parents can refuse bone marrow transplants to their dying children; and many people are reluctant to authorise organ removal at brain death, even though doing so could save countless lives. In each case third parties are entitled to use their powers of moral suasion to convince misguided people to rise above their self centred concerns, but in no case are third parties entitled to compel assent. Pregnant women also retain the right to control events within their bodies, even when their choices fall short of the morally ideal.

Marquis's arguments concerning the welfare rights a decent society would provide for the mentally and physically disabled do not affect this conclusion. Marquis is careful throughout his discussion of these cases to exclude from consideration the kind of welfare rights to bodily integrity that the future like ours argument requires. ${ }^{5}$ He speaks rather of the ideals of a just society to care for its most helpless members and the character of people who choose not to 
donate their bodies to the welfare of others. Nowhere in this part of his critique does he address the crucial issue of the scope of welfare rights. As Marquis seems to recognise, dependents do not in general have enforceable welfare rights to the bodily fluids and internal organs of unwilling potential donors, even if, as is often the case, some desperately ill people will die as a result.

\section{SELF-REPRESENTED FUTURES}

Healthy, mature human beings, unlike animals, fetuses and those who suffer profound neurological damage, can project themselves into the past in memory and into the future in hopes, fears, and intentional actions. Our lives are important in part because we plan for the future, undertake long term projects and understand our own mortality. We are such stuff as dreams are made of. To kill an actual person deprives her of her remembered past and anticipated future. Killing a person causes him serious harm for this reason, although homicide is wrong for other reasons as well. Deprivation of selfrepresented futures is a sufficient but not a necessary condition for the wrongness of killing persons.

Marquis's response to the self-represented futures limb of the equivocation objection to the future like ours argument centres upon two flawed interpretations of the expression "self-represented future". A future interpretation of selfrepresented future would attribute the value of hopes, dreams and plans to future states of affairs in which the anticipated future actually occurs. A present interpretation locates self-represented futures in the current mental state of a person. Marquis is correct that a future interpretation collapses the distinction between potential futures of value and self-represented futures of value, but incorrect in attributing such an interpretation to me. In support of a future interpretation of self-represented futures, Marquis cites the following passage from The morality of abortion and the deprivation of futures ${ }^{6}$ : "Killing a person deprives her of her future; her hopes and dreams are dashed, her goals unfulfilled, her sins unforgiven, longed for reunions never occur".

Marquis omits the very next sentence: "All of this happens in the present, to a person able to unite in a moment of self consciousness a personal past, present and future". ${ }^{6}$ If this were not enough to rule out a future interpretation of self-represented future to a sympathetic reader, the sentence immediately preceding the quoted passage reads: "The value of a self-represented future resides within the person herself, as a feature of a richly complex mental life". ${ }^{6}$ Plainly, on the intended interpretation, self-represented futures refer to present events occurring within the mind of a person.

Suppose, Marquis asks, that the imagined future is unrealistic. ${ }^{7}$ Albert dreams of being a doctor but given his record and aptitude, he has little chance of being admitted to medical school. Is he harmed by the loss of his selfrepresented future if it never would have happened anyway? Yes, he is. Albert's dreams are important to him, and important to the people who care about Albert, whether or not they come true. It is gratifying if our projects meet with success but our hopes and dreams define who we are at the time we have them. Failures and disappointments can be among the most meaningful events in a person's life.

Consider briefly three other putative counterexamples to a self-represented future account of the wrongness of homicide. Suppose a patient has severe bipolar disorder and cannot represent to herself a valuable future. ${ }^{7}$ Does she retain the right not to be killed? Certainly. The self-represented future account presents one sufficient condition among others for the wrongness of homicide. Suppose Charlie is a happy go lucky fellow who gives no thought for the morrow. ${ }^{7}$ Is he harmed by the loss of self-represented futures? If Charlie is literally like an animal with the time horizons of a cow chewing its cud, then Charlie is a much diminished human being who sadly cannot be harmed in this way. If Charlie thinks his attitude has an appealing zen-like bohemian quality while he shrewdly pursues his pleasures, then Charlie's plans are as much a part of who he is as Albert's dreams are a part of him. Does a selfrepresented futures interpretation of the future of value mean that an oncologist who dispels the false hopes of her patient has done something almost as serious as killing him? ${ }^{8}$ of course not. Every doctor knows that a patient who has lost hope faces a grim prognosis, but physicians also know that patients can be brought to re-imagine their future within the confines of their true medical condition and to take steps to make their remaining days meaningful. Self-represented futures by their nature can be revised, updated and replaced. Indeed, part of what it means to be a good doctor is to help patients reconstruct their anticipated future so that they can see their lives as valuable.

Marquis considers a present version of the self-represented future of value account of the wrongness of homicide but implausibly interprets mental representations of the future as momentary mental states, rather like acute pains, tickles and sneezes. ${ }^{7}$ Such mental events last only so long as they are consciously entertained and do not distinguish human persons from animals, or for that matter, a late term fetus.

It makes much more sense to think of intentions, hopes, dreams, fears, contingency planning and other mental representations of the future as dispositional mental states that constrain behaviour and define character whether not they are at the forefront of consciousness. Many of the most significant mental states of persons are dispositional: a physician retains her surgical skills when not operating, has her wry sense of humour when not making jokes, remembers how to diagnose conditions not presented, and likes chocolate ice cream while she enjoys vanilla. Similarly, unrealistic Albert still dreams of being a doctor even though he rarely studies medicine; an estranged lover hopes for an apology but resolves not to brood upon the matter; and I fully intend to mow the grass sometime next week but I probably won't think of it again until Tuesday morning. These and other self-represented futures are dispositional mental states that persist over days, years or decades and enable human persons to invest their lives and the lives of others with meaning and value. They distinguish us from non-human life and from human life before the onset of self consciousness and after its loss. To deprive a human person of their self-represented future is to deprive them of much of what constitutes their basic humanity and personal identity, but it is not a harm that can befall a fetus. Abortion cannot be wrong because it deprives the fetus of its disposition to represent its future because the fetus has no such dispositional mental state. Thus, the future like ours argument fails if future of value is understood to mean a selfrepresented future. And, the future like ours argument fails if future of value is understood to mean potential future of value because people do not have welfare rights to one another's bodies. The equivocation objection stands. The future like ours argument is unsound.

\section{CONCLUSION}

Marquis abandons reference to futures of value in the final statement of his anti-abortion argument. ${ }^{8}$

\section{Marquis's welfare rights argument}

Premise 1: All individuals who possess whatever property it is that makes it wrong to kill them are individuals who (almost always) have a right to the means necessary to sustain their lives.

Premise 2: Fetuses possess a property that makes it wrong to kill them.

Conclusion: Fetuses (almost always) have a right to the means necessary to sustain their lives. 
The crux of this entire debate is the parenthetical qualification "almost always". The exception Marquis recognises is self defence: if an individual needed a heart transplant and threatened to extract a transplantable heart from someone else, that person would be entitled to kill the individual to save his own life. Similarly, even on Marquis's account, a woman has the right to terminate a pregnancy that puts her life at risk. Proponents of a pro-choice view hold that there is a second exception to premise 1: bodily integrity. If an individual needed a kidney transplant and threatened to extract a kidney from someone else, leaving that person otherwise unharmed, the person would have the right to kill the individual if need be to prevent the invasion of bodily integrity. In this case, the conclusion of Marquis's welfare rights argument would be: fetuses (almost never) have the right to the means necessary to sustain their lives. The only exception, assuming the soundness of the argument, would be late term caesareans, and mandatory caesareans introduce a host of issues beyond the scope of this essay. ${ }^{9}$

\section{APPENDIX}

I discuss here two logical errors in Marquis's critique of my original essay, primarily because Marquis puts such emphasis upon them. First, in what Marquis calls "a major internal problem" in my analysis, he notes that any reasons to believe premise 2 of the welfare rights argument (or the complete form of the argument presented in the body of this essay) are reasons to believe premise 1 is false. ${ }^{10}$ This is true, but it is a perfectly general logical feature of any argument of the form modus tollens. Modus tollens arguments consist of a conditional statement, a statement that denies the truth of the consequent of the conditional, and a conclusion that denies the truth of the antecedent: Modus tollens

If $\mathrm{P}$ then $\mathrm{Q}$

It is false that $\mathrm{Q}$

Therefore it is false that $\mathrm{P}$.

The second premise in modus tollens always denies the consequent of the conditional of the first premise, regardless of the subject matter of the argument. Modus tollens is a valid argument form, and the argument I presented is an application of modus tollens.

Second, Marquis attributes to me an "absurd", "bizarre", and "terribly wrong" view on the basis of the following reasoning:

[l]f one considers only the victim, then all individuals having a right not to be killed also have a welfare right to be provided with what they need to stay alive. Now add Brown's claim that there is no welfare right to be provided with what one needs to stay alive. It follows that no one has the right not to be killed!"
This passage commits the formal fallacy of denial of conjunction. The first sentence is a conditional with a conjunction as its consequent. The truth of the antecedent is assumed: One should consider only the victim. The conjunction is detached by the valid argument form modus ponens. The second sentence is the denial of one of the conjuncts of the consequent: it is false that there is a welfare right to be provided with what one needs to stay alive. The conclusion is supposed to be that no one has the right not to be killed.

Modus ponens

If $\mathrm{P}$ is true then both $\mathrm{Q}$ and $\mathrm{R}$ are true.

$P$ is true.

Therefore, Q and R are true.

So far Marquis makes no logical mistakes, although one might wonder if the truth of $\mathrm{P}$, that one must consider only the victim, is so obvious that it need not be stated. The next step is a logical error. From the falsehood of $\mathrm{R}$ - there is no welfare right to what one needs to stay alive-and the truth of the conjunction Q \& R-it is true that individuals have a right not to be killed and that individuals have a welfare right to what they need to stay alive-all that follows as a matter of logic is that the conjunction is false. Nothing can be inferred regarding the truth of the remaining conjunct.

Denial of conjunction fallacy

It is true that both $\mathrm{Q}$ and $\mathrm{R}$

$\mathrm{Q}$ is false.

Therefore, $\mathrm{R}$ is false.

To see why this is a logical error, suppose the conjunction were George W Bush is president of the United States and his brother Jeb is the governor of Texas. Jeb is the governor of Florida, not Texas, but it does not follow that George W Bush is not the president of the United States. Similarly, one cannot validly infer the falsehood of the claim that people have a right not to be killed from the falsehood of one of the conjuncts in a conjunction in which it is embedded.

\section{REFERENCES AND NOTES}

1 Brown M. The morality of abortion and the deprivation of futures. Journal of Medical Ethics 2000;26:103-7. The future like ours argument was first published in: Marquis D. Why abortion is immoral. Journal of Philosophy 1989;86:183-202.

2 Marquis D. Deprivations, futures and the wrongness of killing. Journal of Medical Ethics 2001;27:363-9.

3 See reference 2: 363 .

4 See reference 2: 364 .

5 See reference 2: 365 .

6 Brown $M$. The morality of abortion and the deprivation of futures. Journal of Medical Ethics 2000;26:103-107, at 105.

7 See reference 2: 367

8 See reference 2: 368 .

9 For a discussion of these issues, see: Rhoden N. Caesareans and samaritans. Law, Medicine \& Health Care 1987:3:1 18-25.

10 See reference 2: 365 .

11 See reference 2: 366 . 